\title{
Atividade biológica da jurema-preta (Mimosa tenuiflora (Wild) Poir.) sobre Staphylococcus aureus isolado de casos de mastite bovina
}

\author{
Denise A. C. Bezerra, ${ }^{1}$ Andréia. V. Pereira, ${ }^{1}$ Katiuscia M. S. Lôbo, ${ }^{1}$ Onaldo G. Rodrigues, ${ }^{*, 2}$ \\ Ana C. R. Athayde, ${ }^{2}$ Rinaldo A. Mota, ${ }^{3}$ Elizabeth. S. Medeiros, ${ }^{3}$ Sheina Campos Rodrigues ${ }^{2}$ \\ ${ }^{1}$ Programa de Pós-graduação em Zootecnia, Universidade Federal de Campina Grande, Av. Universitária s/n, \\ Bairro Santa Cecília, 58708-110 Patos-PB, Brasil \\ ${ }^{2}$ Laboratório de Ciências Químicas e Biológicas, Unidade Acadêmica de Ciências Biológicas, Universidade \\ Federal de Campina Grande, Av. Universitária s/n, Bairro Santa Cecília, 58708-110 Patos-PB, Brasil \\ ${ }^{3}$ Laboratório de Doenças Infecto Contagiosas, Universidade Federal Rural do Pernambuco, Rua Dom Manuel \\ de Medeiros s/n, Dois Irmãos, 52071-030 Recife-PE. Brasil
}

\begin{abstract}
RESUMO: O objetivo deste estudo foi avaliar a sensibilidade do Staphylococcus aureus ao extrato da jurema-preta (Mimosa tenuiflora (Wild) Poir.). Foram isoladas 25 cepas de $S$. aureus de amostras de leite de vacas com histórico de mastite clínica e subclínica, submetidas ao teste de atividade antimicrobiana do extrato de $M$. tenuiflora. Os testes de sensibilidade in vitro foram realizados utilizando o método de difusão em meio sólido. Em seguida foram inoculados $50 \mu \mathrm{L}$ do extrato nas seguintes diluições $1: 1 ; 1: 2 ; 1: 4 ; 1: 8 ; 1: 16 ; 1: 32 ; 1: 64 ; 1: 128 ; 1: 256 ; 1: 512$. As placas foram incubadas a $37^{\circ} \mathrm{C}$, por um período de 24 a $48 \mathrm{~h}$. Os ensaios foram realizados em triplicata. Observou-se halos de inibição entre 6 e $25 \mathrm{~mm}$ de diâmetro. O percentual de sensibilidade das amostras testadas foi distribuido em: 1:1 a 1:32 (100\%); 1:64 (92\%); 1: 128 (72\%); 1:256 (28\%); 1:512 (0\%). O estudo da M. tenuiflora sobre as amostras de $S$. aureus testadas demonstrou que a planta tem ação antimicrobiana.
\end{abstract}

Unitermos: Jurema-preta, Mimosa tenuiflora, sensibilidade bacteriana, produtos naturais, bovinos.

\begin{abstract}
Biological Activity of jurema preta (Mimosa tenuiflora (Wild) Poiret) on Staphylococcus aureus isolated of mastitis cattle." The aim of this study was to evaluate the sensitivity of the S.aureus to the extract of Mimosa tenuiflora (Wild) Poir. (jurema-preta). Twenty five strains of $S$. aureus were isolated from milk samples with description of clinical and subclinical mastitis and submitted to antimicrobial activity test of the $M$. tenuiflora extract. The sensitivity in vitro tests were carried out using the agar difusion method (well diffusion method). After that, $50 \mu \mathrm{L}$ of the extract were inoculated in the following dilutions: $1: 1 ; 1: 2 ; 1: 4 ; 1: 8 ; 1: 16 ; 1: 32 ; 1: 64$; $1: 128 ; 1: 256 ; 1: 512$. The plates were incubated at $37^{\circ} \mathrm{C}$ during 24 and $48 \mathrm{~h}$. The tests were made in triplicate. Halos of inhibition were observed between 6 and $25 \mathrm{~mm}$ of diameter. The percentage of sensitivity of the tested samples was distributed in: $1: 1$ to $1: 32(100 \%), 1: 64(92 \%) ; 1: 128$ $(72 \%) ; 1: 256(28 \%) ; 1: 512(0 \%)$. The study of $M$. tenuiflora on the tested $S$. aureus samples it demonstrated that the plant has antimicrobial action.
\end{abstract}

Keywords: jurema-preta, Mimosa tenuiflora, bacterial sensitivity, natural products, cattle.

\section{INTRODUÇÃO}

Em medicina veterinária o gênero Staphylococcus é o prevalente agente causador de mastites. Houve um grande emprego de antibióticos no tratamento das mastites, resultando em seleção de cepas resistentes aos mesmos, aumentando o número de casos provocados por outros germes não habitualmente ligados a esses processos. Além dos altos custos com o tratamento, há uma preocupação crescente com a presença de resíduos de antibióticos no leite, estimulando uma busca de métodos alternativos para a abordagem clássica dos antibióticos (Costa et al., 1985). Atualmente, 95\% das cepas de Staphylococcus aureus, de todo o mundo, são resistentes à penicilina, ampicilina e penicilina antipseudomonas. A indústria farmacêutica respondeu a esta crise com a síntese da methicilina (penicilina semi-sintética). Mas desde 1980 tem-se notado o aumento da resistência de S.aureus a este 
antibiótico em vários hospitais do mundo (Neu, 1992). A resistência bacteriana aos antibióticos é mundial. Os riscos da transmissão de bactérias resistentes para o homem é extremamente efetivo através da alimentação (WHO, 1997).

Devido ao intenso uso das plantas na medicina popular, desde as épocas mais remotas, estas têm sido valorizadas como produtos naturais importantes para a manutenção da saúde humana, especialmente na ultima década, com a realização de muitos estudos sobre terapias naturais (Corrêa et al., 2001). As propriedades terapêuticas dos princípios e medicamentos fitoterápicos começam a ganhar cada vez mais espaço no tratamento veterinário, profissionais adeptos da fitoterapia revelam alta freqüência de sucessos em tratamento de parasitoses e enfermidades infecciosas, inclusive em tratamentos de mastites (Costa et al., 1985)

A jurema-preta pertence à família Leguminosae e subfamília Mimosoidae, característica da Caatinga, e apresenta grande potencial de produção de forragem constituindo, na maioria das vezes, a principal fonte de alimentação animal nesta região (Caldas Pinto, 2006). É também utilizada como madeira e carvão, bem como na medicina caseira, em tratamentos de queimaduras, acne e problemas de pele (Maia, 2004).

Da casca da M. tenuiflora (Willd.) Poir., foram isolados vários compostos com atividade biológica que vêm sendo estudadas e publicadas nos últimos anos, dando cada vez mais destaque à espécie nos avanços do conhecimento químico-farmacológico. A abundância de taninos e flavonóides detectados no extrato acetato de etila de $M$. tenuiflora são os prováveis responsáveis pela atividade antimicrobiana da planta (Meckes-Lozoya et al., 1990).

Diante do potencial antimicrobiano desta planta este estudo teve como objetivo avaliar a sensibilidade do $S$. aureus isolado de casos de mastite clínica e subclínica em bovinos ao extrato da $M$. tenuiflora.

\section{MATERIAL E MÉTODOS}

O experimento foi conduzido no Laboratório de Ciências Químicas e Biológicas da Universidade Federal de Campina Grande, Centro de Saúde e Tecnologia Rural, e no Laboratório de Doenças Infecto Contagiosas da Universidade Federal Rural do Pernambuco. Foi realizada a coleta da jurema-preta na fazenda do Núcleo de Pesquisa para o Desenvolvimento do Semi-árido, pertencente à Universidade Federal de Campina Grande, no município de Patos-PB. A parte da planta utilizada no estudo foi a casca. A identificação botânica e preparação de exsicata foi realizada no Herbário Caririensis Dárdano de Andrade Lima na Universidade Regional do Cariri, Crato-CE, pela botânica curadora do Herbário, Profa. Dra. Maria Arlene Pessoa da Silva. A exsicata foi depositada no herbário sob o No. \#3275.
Após a colheita e identificação botânica as amostras foram acondicionadas em sacos de papel comum, aerados e em seguida postas para secagem em estufa de ventilação forçada a $40^{\circ} \mathrm{C}$. Após $72 \mathrm{~h}$ a amostra foi moída e acondicionada em reservatórios de vidro estéreis até seu uso.

\section{Obtenção do extrato etanólico}

Os extratos foram obtidos a partir de $500 \mathrm{~g}$ do material seco e moído e adicionado $1000 \mathrm{~mL}$ de etanol PA., segundo a metodologia descrita por Matos (1997). A concentração final do extrato da jurema-preta foi de $0,5 \mathrm{~g} / \mathrm{mL}$ com rendimento de $57 \mathrm{~g}$ de extrato bruto. Para os ensaios, foi utilizado o extrato bruto nas seguintes diluições: $1: 1 ; 1: 2 ; 1: 4 ; 1: 8 ; 1: 16 ; 1: 32 ; 1: 64 ; 1: 128 ; 1: 256$; $1: 512$.

\section{Aquisição de amostras de animais infectados}

Utilizou-se cem vacas de diferentes estágios de lactação primíparas e multíparas. Os animais apresentavam boas condições de saúde, eram alimentados e suplementados adequadamente e recebiam sal mineral e água ad libitum. Foram coletadas amostras de $5 \mathrm{~mL}$ de leite por cada quarto mamário de maneira asséptica, totalizando quatrocentas amostras segundo a metodologia de Bouchot et al. (1985), para a realização do exame microbiológico, e identificação do $S$. aureus e encaminhadas, sob refrigeração, ao Laboratório de Doenças Infecto-Contagiosas da Universidade Federal Rural de Pernambuco.

\section{Exames microbiológicos}

A lactocultura foi feita em placas contendo ágar base acrescido de $8 \%(\mathrm{v} / \mathrm{v})$ de sangue ovino desfibrinado. As placas foram incubadas em aerobiose a $37^{\circ} \mathrm{C}$, em estufa microbiológica e analisadas após 24 e 48 h (NMC, 1990). Foram observadas as características de crescimento das colônias em placa, como produção de hemólise, pigmento e características morfo-tintoriais, utilizando o método de coloração pela técnica de Gram. A classificação das bactérias Gram positivas foi realizada de acordo com Quinn et al. (1994).

\section{Identificação das cepas de Staphylococcus aureus}

Para a identificação de $S$. aureus todas as cepas de estafilococos foram submetidas aos testes de produção de coagulase livre (Plasma Coagulase EDTA, Coagu-Plasma LB - Laborclin, Brasil), DNAse (Agar DNAse - DFICO) e catalase (Silva et al., 1997). As provas de produção de acetoína, fermentação da glicose (aerobiose) e do manitol (aerobiose e anaerobiose) foram realizadas segundo Mac Faddin (1980) e os isolados, classificados de acordo com Baird-Parker (1990). 


\section{Estudo da atividade antimicrobiana da jurema-preta}

As linhagens foram cultivadas em caldo nutritivo (BHI- Brain Heart Infusion - DIFCO); incubadas a $37^{\circ} \mathrm{C}$ por $24 \mathrm{~h}$. A atividade antimicrobiana foi determinada pelo método de difusão em meio sólido para a determinação da Concentração Inibitória Mínima (CIM) do extrato alcoólico de M. tenuiflora sobre as linhagens bacterianas. Utilizou-se orifícios de $6 \mathrm{~mm}$ de diâmetro os quais foram preenchidos com $50 \mu \mathrm{L}$ da solução do extrato diluída em água destilada, nas concentrações pré-estabelecidas. A sensibilidade da amostra foi considerada para medidas de halos superiores a $12 \mathrm{~mm}$. Os ensaios foram realizados em duplicata acompanhados de controle positivo com o antibiótico amoxilina $(10 \mathrm{mg})$ e como controle positivo e disco embebido com etanol $70 \%$ controle negativo $(\mathrm{CECON} / \mathrm{SP})$. As placas foram incubadas em estufa bacteriológica a $37^{\circ} \mathrm{C}$ por um período de $24 \mathrm{~h}$ e a leitura efetuada após 24 e $48 \mathrm{~h}$. Foi considerada como CIM a menor concentração do extrato que inibiu completamente o crescimento bacteriano, observada pela presença do halo de inibição. (Silva et al, 2003).

\section{RESULTADOS E DISCUSSÃO}

Os resultados demonstraram a eficácia do extrato de $M$. tenuiflora sobre cepas de $S$. aureus em diferentes concentrações, sendo observado halos de inibição entre 6 e $25 \mathrm{~mm}$. Das amostras testadas, as diluições de 1:1; $1: 2 ; 1: 4 ; 1: 8 ; 1: 16$ e $1: 32$ apresentaram halos superiores ao halo mínimo de $12 \mathrm{~mm}$ estabelecido por Silva et al. (2003), enquanto que as diluições $1: 64 ; 1: 128 ; 1: 256$; 1:512 apresentaram percentual de atividade de $92 \%, 72 \%$, $28 \%$ e $0 \%$ respectivamente. O microrganismo testado não apresentou halo de inibição no disco controle negativo embebido com álcool $70 \%$ e no teste controle positivo o microrganismo foi resistente em $28,8 \%$ das amostras, e apresentou um percentual de sensibilidade de $53,7 \%$.

Observou-se que a diluição é inversamente proporcional a eficácia do extrato, como demonstram os resultados obtidos por Heinrich et al. (1992), onde cepas de Streptococcus sp. e Staphylococcus sp foram sensíveis ao extrato de M. tenuiflora, apresentando uma redução na atividade biológica: 1:64 (90\%); 1:128 (80\%); 1:256 $(65 \%) ; 1: 512$ (45\%). Em estudos realizados por Pereira et al. (2009a), os extratos etanólicos de M. tenuiflora foram utilizados no tratamento de búfalas com diagnóstico de mastite clínica e subclínica, apresentando ser eficaz no tratamento da doença causada por cepas de $S$. aureus coagulase positivo e negativo quando comparado ao extrato de Azadiracta indica, confirmando os resultdos obtidos. Os resultados deste estudo demonstraram a eficácia do extrato de M. tenuiflora em diferentes concentrações, corroborando com os resultados obtidos por Pereira et al. (2009b) que avaliou o extrato de M.tenuiflora, Caesalpinia férrea e Punica granatum observando que os halos de inibição formados pelo extrato da M. tenuiflora variaram entre 6 e $30 \mathrm{~mm}$ e foram superiores aos encontrados nas outras espécies e ao apresentado pelos antibióticos penicilina e azitromicina cujos os halos foram entre $5-9 \mathrm{~mm}$.

A atividade antimicrobiana do extrato de jurema-preta pode estar vinculada a presença de taninos e flavonóides nessa parte da planta como descrito por Meckes-Lozoya et al. (1990). Essa atividade também foi verificada em Staphylococcus epidermitis, Escherichia coli, Pseudomonas aeruginosa, Micrococcus luteus e Acinetobacter calcoaceticus, além de fungos como Microsporum gypseum, M. canis, Thrichophyton mentagrophytes, T. rubus e Chaetomium indicum (Lozoya et al., 1989). Em extrato hidroalcoólico de jurema preta, Gonçalves et al. (2005) demonstraram que houve atividade sobre $S$. aureus e $P$. aeruginosa, obtendo resultados que confirmam a sensibilidade destes microrganismos ao extrato da planta.

Trabalhos posteriores realizados em 2006, pelo mesmo autor demonstraram que a jurema-preta apresentou excelente atividade antimicrobiana contra Staphylococcus aureus, Staphylococcus spp coagulase negativa e outros microorganismos formando halos de inibição de 23 e 12 $\mathrm{mm}$ respectivamente. Em estudos utilizando extrato de M. tenuiflora, Heinrich et al. (1992) também verificou a sua atividade antimicrobiana sobre cepas de Streptococcus spp., Staphylococcus apresentando também eficácia sobre Proteus mirabilis e Shigella sonnei.

\section{CONCLUSÃO}

O estudo da Mimosa tenuiflora sobre amostras de Staphylococcus aureus identificadas e isoladas de leite de vacas com histórico de mastite clínica ou subclínica, demonstrou que a mesma tem ação antimicrobiana, sendo, portanto uma confirmação do potencial deste extrato para a possível utilização dessa planta como indicação terapêutica.

\section{REFERÊNCIAS}

Baird-Parker AC 1990. The Staphylococci: an introduction. $J$ Appl Bacteriol 19: 15-85.

Bouchot MC, Catel J, Chirol C, Ganiere JP, Menec ML 1985. Diagnostic bactériologique dês infections mammaries des bovins. Rec Med Vet 19: 567-577.

Caldas Pinto MS, Borges Cavalcante M A, Meira de Andrade MV. 2006. Potencial forrageiro da caatinga, fenologia, métodos de avaliação da área foliar e o efeito do déficit hídrico sobre o crescimento de plantas. Rev Eletr Vet 7: 1-10.

Corrêa AD, Batista RS, Quintas LE 2001. Plantas Medicinais: do cultivo à terapêutica. Petrópolis: Vozes.

Costa EO, Coutinho SD, Castilho W 1985. Sensibilidade a antibióticos e quimioterápicos de bactérias isoladas de mastite bovina. Pesq Vet Bras 5: 65-69. 
Gonçalves AL, Alves Filho A, Menezes H 2005. Estudo comparativo da atividade antimicrobiana de extratos de algumas árvores nativas. Arq Inst Biol 72: 353-358.

Gonçalves AL, Alves Filho A, Menezes H 2006. Efeitos antimicrobianos de algumas árvores medicinais nativas nas conjuntivites infecciosas. Biologico 68: 134-139.

Heinrich MM, Kuhnt M, Wrigt CW, Rimpler H, Phillipson JD, Schandelmaier A, Warhurst DC 1992. Parasitological and microbiological evaluation of mixe indian medical plants. J Ethnopharmacol 36: 81-85.

Lozoya X, Navarro V, Arnason JT, Kourany E 1989. Experimental evaluation of Mimosa tenuiflora (Willd) Poir. (tepescohuite) I - Screening of the antimicrobial properties of bark extracts. Arch Invest Med 20: 87-93.

Mac Fadin J 1980. Pruebas bioquímicas para la identification de bactérias de interesse clínico. Buenos Aires. Panamericana.

Maia GN 2004. Caatinga - árvores e arbustos e suas utilidades. São Paulo D\&Z Computação Gráfica e Editora. p.237246.

Matos FJA 1997. Introdução à fitoquímica experimental. UFC Edições.

Meckes-Lozoya M, Lozoya X, Marles RJ, Soucy Breau C, Sen A, Arnason JT 1990. N,N-Dimenthyltryptamine alkaloid in Mimosa tenuiflora Bark (Tepescohuite). Arch Inv Med 2: $175-177$.

NMC 1990. Microbiological procedures for the diagnosis of bovine udder infection. National Mastitis Council $34 \mathrm{p}$.

Neu HC 1992. The crisis in antibiotic resistance. Science 257: 1064-1074.

Pereira AV, Lôbo KMS, Bezerra DAC, Rodrigues OG, Athayde ACR, Mota RA, De Lima EQ, De Medeiros ES 2009a. Perfil de sensibilidade antimicrobiana in vitro de juremapreta e neem sobre amostras de Staphylococcus sp. isoladas de mastite em búfalas. Arq Inst Biol 76: 341346.

Pereira AV, Rodrigues OG, Azevêdo TKB, Bezerra DAC, De Lima EQ, Pereira MS 2009b. Perfil de extrato de plantas sobre Staphylococcus aureus isolado de mastite bovina. Rev Biol Farm 3: 1-5.

Quinn PJJ, Carter ME, Markey B, Carter GR 1994. Clinical Veterinary Microbiology. Philadelphia: Mosby, p.170174.

Silva MAR 2003. Influência do extrato da romã (Punica granatum Linn.) sobre plasmídeos nos processos de cura e transmissibilidade genética de Staphylococcus aureus de origem bovina. $49^{\circ}$ Congresso Brasileiro de Genética, Gramado, RS.

Silva N, Junqueira VCA, Silveira NFA. 1997. Manual de métodos de análise microbiológica de alimentos. São Paulo: Varela, p. 295.

WHO 1997. The medical impact of antimicrobial use in foods animals. Report of a WHO Meeting. Berlim, Germany. 13-17 October (WHO/EMC/ZOO/97.4). 